\title{
Labour Productivity Measures from the ABS: 1998 to 2009
}

\section{Author Name(s): Jean Acheson, ONS}

\begin{abstract}
This article compares micro and macro measures of productivity. Detailed industry-level productivity estimates are key to understanding how the aggregate economy is driven by the performance of particular sectors, and also how certain sectors perform relative to others. A detailed focus is all the more important in the aftermath of the UK's deepest recession since the 1930s. This article aims to aid the analysis of the economy over the recession and comment on which specific industries saw the biggest changes. The article updates the work of Long (2010) by adding two additional years of data from the Annual Business Survey (ABS), 2008 and 2009.
\end{abstract}

\section{Acknowledgements}

1. The author thanks Mark Franklin, John Appleton, Sian Summers, Steve Taylor, Chris Hunt and Matthew Hughes for their help in producing this article.

\section{Introduction}

The Annual Business Survey (ABS), formerly known as the Annual Business Inquiry (ABI), is an annually conducted business survey which covers the market sector of the economy but excludes part of agriculture, forestry and fishing and most of financial services. ${ }^{1}$ It brings together employment and financial data into one dataset where previously this was collected using various different surveys. ${ }^{2}$ This allows the aggregates to be produced using a common methodology, resulting in greater consistency between input and output data. Coherent estimates of nominal value-added per job can consequently be produced at a detailed level.

The ABS estimates cover UK businesses registered for VAT and/or PAYE, classified to SIC 2007. ${ }^{3}$ There are two sources for the ABS: one is the Business Register Employment Survey (BRES) which provides the employment data and $A B I / 2$, which provides the financial data. ${ }^{4}$ Both surveys use different samples taken from the Interdepartmental Business Register (IDBR), but are merged together at the four or five-digit SIC level. ${ }^{5}$ 
The significant change in industrial classification over the ABS time series - SIC 2007 was introduced in the 2008 publication - meant that a choice had to be made over how to characterise the industrial breakdown of the data for this article. It was not possible to accurately convert the back series, 1998 to 2007, to SIC 2007 as not all firms sampled over this time period have remained on the IDBR and thus have a SIC 2007 converter variable associated with them. As both the 2008 and 2009 employment data from BRES were readily available on both SIC 2003 and SIC 2007, it was felt that, for the sake of accuracy, converting two years of financial data from ABI/2 to SIC 2003 would achieve more accurate results than converting ten years of both datasets to SIC 2007. As such, any reference to National Accounts industry-level data in this article is consistent with Blue Book 2010, rather than Blue Book 2011, as 2010 was the last Blue Book to be published on a SIC 2003 basis.

\section{Notes}

1. You may use or re-use the information in this article (not including logos) free of charge in any format or medium, under the terms of the Open Government Licence. To view this licence, visit http://www.nationalarchives.gov.uk/doc/open-government-licence/or write to the Information Policy Team, The National Archives, Kew, London TW9 4DU, or email: psi@nationalarchives.gsi.gov.uk.

2. These were the Annual Employment Survey, Annual Census of Production, Annual Census of Construction and Distribution and Service Inquiries.

3. Standard Industrial Classifications (SIC) are an internationally agreed system of classifying firms into different industries. From October 2011, all ONS data are published on a SIC 2007 basis. A SIC 2003 reference table is provided in Table A5 of this article.

4. For 2009 data onward, i.e. for the 2008 publication, BRES replaced $\mathrm{ABI} / 1$ as the employment survey used in the publication of the ABS.

5. The IDBR is a register that consists of companies, partnerships, sole proprietorships, public authorities, central government departments, local authorities and non-profit making bodies. The main administrative sources of the IDBR are HMRC for VAT and PAYE details.

\section{ONS Productivity Measures}

The ONS Productivity branch produces three types of productivity statistics: International Comparisons of Productivity; experimental multi-factor productivity statistics; and the quarterly Labour Productivity Statistical Bulletin. ${ }^{1}$ Currently the Labour Productivity Statistical Bulletin provides results for the main sectors of the economy and sub-sectors of manufacturing. However, an examination of productivity performance at a lower level provides a clearer picture of its drivers and dynamics across industries. This picture is particularly important in light of the recent recession; while whole economy output per worker fell by 5.1 per cent from Q1 2008 to Q2 2009 and has yet to recover to its pre-recession levels, performance varied across industries, with services seeing a much smaller decline in productivity than manufacturing. ${ }^{2}$ 
The labour productivity estimates in the Labour Productivity Statistical Bulletin differ from those presented in this article. Firstly, the Bulletin estimates use output measures from the National Accounts and, on the labour input side both employees and the self-employed, with the latter not picked up on ABS. The National Accounts output data are subject to coherence and balancing adjustments that may result in reduced consistency between the output and input data. ${ }^{3}$ In contrast, the estimates presented in this article are based on ABS data that have not undergone such National Accounts adjustments. Additionally the estimates presented in the Statistical Bulletin are in constant prices, whereas those presented here are in both current and constant prices. While the current price format does not allow for the analysis of trends in productivity over time, it does facilitate comparisons in the levels of productivity across industries for a given year. The constant price results, on the other hand, allow a picture of productivity prior to and during the recession to emerge. ${ }^{4}$ Most importantly, the estimates presented in this article contain a more detailed industry breakdown than is available in the statistical bulletin. This detailed information is contained in Table A3.

\section{Notes}

1. Further details are provided in the guide to productivity measures at: http://www.ons.gov.uk/ ons/rel/icp/productivity-measures/guide-to--labour-productivity-measures/sum-guide-to--prodmeasures.html

2. Calculation based on the Labour Productivity Q2 2011 publication using series A4YM (output per worker, whole economy SA, index 2008=100). The peak quarter is 2008 Q1 and the trough is 2009 Q2, quarters taken from Quarterly National Accounts $2^{\text {nd }}$ Quarter 2011 publication.

3. More detail on these adjustments may be found in previous ABS labour productivity articles.

4. The method of deflation used in this article, and generally throughout the ONS, assumes that intermediate consumption is a constant share of gross output. This assumption allows gross value added to be deflated, whereas the ideal method of deflation - double deflation - would deflate gross output and intermediate consumption separately.

\section{The ABS Survey}

The published ABS data, on which these labour productivity estimates are based, can be found on the ONS website. Finalised data are available 18 months after the end of a given reference year. The most recent finalised data available relate to the 2009 reference year. It is important to note that $A B S$ revisions arising from quality and omissions issues are only taken back two years.

This means that the ABS is only consistent on a rolling basis for the reference years 2008 and 2009. This should be borne in mind when interpreting the estimates.

The output measure used in the productivity estimates here is "approximate" gross value added (GVA) in basic prices. ${ }^{1}$ This differs from the GVA estimates resulting from Input-Output analysis which are compiled in accordance with the European System of Accounts (ESA) 95. The primary difference between the two is that approximate GVA omits adjustments for taxes, subsidies or 
payments in kind. Additionally the GVA estimates contained in the Supply-Use framework are subject to conceptual, quality and coherence adjustments, as mentioned previously.

Approximate GVA per job estimates are not available prior to 1998. Although approximate GVA data are available from the ABS from 1995 onward, an employment measure consistent with this is not available until $1998 .^{2}$

\section{Notes}

1. GVA is 'gross' in the sense that it includes capital consumption, and should not be confused with gross output, which includes intermediate consumption.

2. Between 1995 and 1998 employment data was collected using the Annual Employment Survey (AES) which, due to methodological and coding differences, is not consistent with the ABS.

\section{Structure of the article}

The structure of the rest of the article is as follows. The methodology behind the Annual Business Survey estimates is outlined in the next section. Following this, the results are discussed. This discussion falls into two parts. Firstly, results in constant prices are presented. The focus is on broad manufacturing, manufacturing sub-sections, broad services and selected sections of services and, where possible, the ABS results are compared to ONS official estimates of labour productivity. Secondly, the results in current price terms (or nominal results) are discussed, highlighting some cross-sectional and time series features of the detailed four digit level data. Lastly, a conclusion on the ABS results is drawn and areas for further research highlighted.

\section{Methodology}

\section{Producing published variables from the micro data}

Approximate GVA at basic prices and year-average total employment are the two variables used in the productivity calculation. The first step in the methodology for the 2008 and 2009 data was to build these up from other variables in the micro data; for example, the employment variable is built up from aggregating year average employees, working proprietors and unpaid workers. GVA at basic prices is built up from turnover and other financial variables.

\section{Linking data across different industrial classifications}

The two latest years of ABS data, 2008 and 2009, are both published on a SIC 2007 basis. However, the back series, 1998 to 2007, is classified on SIC 2003. In order to create a time series for constant price analysis, the data for 2008 and 2009 were converted into a SIC 2003 
classification. It was necessary to use the ABS micro data, i.e. firm level observations, housed in the ONS Virtual Microdata Laboratory (VML), to perform this conversion, whereas previous ABS labour productivity articles used only the published data.

Each observation in the micro data has a unique identifying number on a reporting unit (RU) basis. Reporting units are the level at which ONS usually collects data from firms. Firms which are part of a larger enterprise do not all necessarily have the same industrial classification by reporting unit. For example, an enterprise consisting of two reporting units, a cake shop and a bakery, will have the former classified as retail and the latter classified as manufacturing. The enterprise will also have a unique identifying number, and its industrial classification will be based on its majority activity. In converting from SIC 2007 to SIC 2003, it is important to do the conversion on an RU basis (if done on an enterprise unit basis, the structure of economic activity at the micro level would be distorted).

For the employment variable it was possible to obtain the micro data on an RU SIC 2003 basis directly from the BRES survey team for both 2008 and 2009. This meant that no conversion of data in the VML was needed for this variable.

For GVA, the RU SIC 2003 universe obtained from the BRES team was merged with the 2008 and $2009 \mathrm{ABI} / 2$ micro datasets in the VML, and this was done by reporting unit. For each observation that merged on this basis we then had both the RU SIC 2007 classification (from the ABI/2 survey) and a corresponding RU SIC 2003 classification (from the employment data obtained directly from the BRES survey team). This merging step converted the vast majority of the $A B I / 2$ observations: 94 per cent of observations in the 2008 and 2009 ABl/2 micro data were merged in this way.

The remaining observations were merged in the VML with an alternative business register database which contained both SIC 2003 and SIC 2007 reporting unit classifications for firms. ${ }^{1}$

\section{Northern Ireland adjustment}

The micro data for both employment and output in 2008 and 2009 do not include Northern Ireland. The published data, on the other hand, refer to the United Kingdom as a whole. Therefore it was necessary to apply an adjustment factor to account for this. This was created by taking a ratio of the published data to the micro data for 2007. 2007 was chosen as it is the last year when both the micro data and published data were both produced on a SIC 2003 basis. The ratios were created on a four and two digit basis. The ratios were applied to both the results produced in the VML (for GVA) and those results produced outside it (employment) for the years 2008 and 2009.

\section{Constant price measures}

In order to analyse productivity at constant prices, GVA at basic prices must be deflated. This is done using the Producer Price Indices (PPI) and Services Producer Price Indices (SPPI). SPPIs capture changes in the price received for services provided by UK businesses to other UK businesses and government. There are a broader range of PPIs produced but only those related 
to output classified by industry are used in this article. Note that this form of deflation only captures domestic price movements and omits price change in export markets. Only broad trends can be inferred from the deflated data as price coverage of the services industries is far from complete and, as mentioned above, ABS estimates are only consistent on a two-year basis.

\section{Quality Issues (Tables 1-3)}

For certain industries, the ABS estimate of approximate GVA per job is judged to be of low quality or is not currently published by the ABS. In these cases the measure has been withdrawn. This applies for the industries shown in Table 1.

Additionally, for the industries listed in Table 2, users should exercise caution when interpreting the results due to volatile estimates of GVA.

Lastly, due to issues with data quality and volatility, industries have been aggregated as shown in Table 3.

In addition, some approximate GVA per job estimates at the four-digit level have been suppressed, due to their disclosive nature. This is also true of those industries where employment is less than 500. Data for these industries are still included within broader aggregates such as industrial sections.

The labour productivity estimates presented in this article use ABS year-average employment as their input measure. This variable is derived by adjusting the ABS point-in-time employment estimate using employment measures from the quarterly STES data. This removes elements of seasonality that may be present in the point-in-time ABS estimates, which refer to the month of September (December prior to 2006). However, it also results in the loss of some consistency between input and output data. It should be taken into account that the labour productivity estimates are based on output per job, as opposed to output per hour worked. This will result in underestimates of productivity for those sectors in which a second job is more prevalent and overestimates for those industries in which it is less prevalent.

\section{Notes}

1. All firms sampled in the ABS (both in BRES and $A B I / 2$ ) are drawn from the Interdepartmental Business Register (IDBR). The IDBR has both a SIC 2003 and a SIC 2007 designation for all its firms and thus if the firm level data from the 2008 and $2009 \mathrm{ABI} / 2$ are merged with it, the 
SIC 2003 character of the data can be created. An edited version of the IDBR was used in this methodology.

\section{Results}

\section{Analysis of deflated value added per job}

\section{1.i. Manufacturing in aggregate}

Constant price productivity estimates from the ABS are not identical to the official estimates in the Labour Productivity Statistical Bulletin. Taking the most directly comparable industry, manufacturing in SIC 2003 terms, productivity grew faster according to the official estimates, and fell by less during the recession (Figure 1).

\section{Figure 1: estimates of manufacturing output per job, SIC 2003}

Index $1998=100$

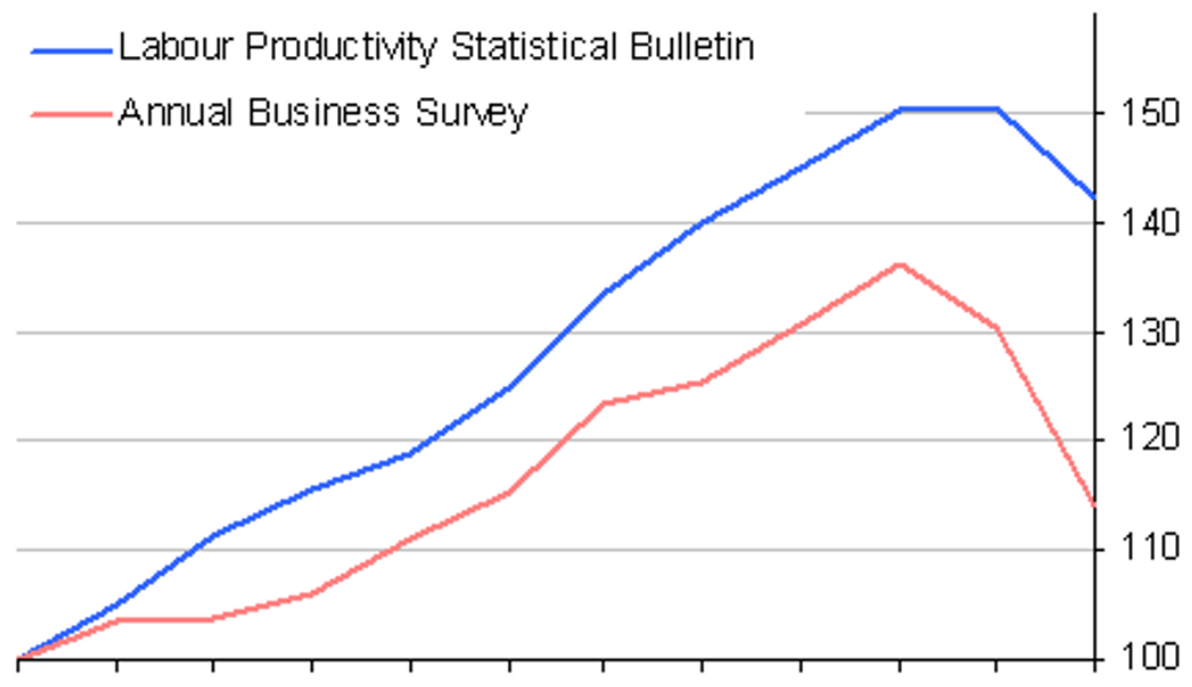

199819992000200120022003200420052006200720082009

Source: Annual Business Survey (ABS) - Office for National Statistics

Notes:

1. As these data are in SIC 2003 terms, the Labour Productivity output per job series (blue line) is taken from the ONS Labour Productivity statistical bulletin of 29 June 2011, and not the release of 6 October 2011, which is published in SIC 2007 terms.

\section{Download chart}

\section{XLS XLS format}

$(36.5 \mathrm{~Kb})$

The size of the disparity may seem surprising given that elements of both the employment and output data in the official productivity statistics are benchmarked to ABS data. On the labour input 
side, employee jobs - the largest component of productivity jobs - are benchmarked to the BRES employee estimates for Great Britain. On the output side, current price Index of Production (IoP) estimates are benchmarked to GVA at basic prices, taken from the ABS. No benchmarking to ABS has been applied in the official estimates beyond 2008 because ABS aggregates are not available on SIC 2003. And for 2008, the ABS aggregates in SIC 2003 terms used to benchmark current price IoP differ somewhat from the VML-based SIC 2003 estimates computed for this article.

In the case of employment estimates, the differences between the underlying series from the ABS and the statistical bulletin are small: the average growth rate over 1998 to 2009 for the former is -3.4 per cent and is -3.8 per cent for the latter (Figure 2). The main explanation for this difference is that the ABS records employees only, whereas the official productivity estimates also include the selfemployed.

The difference in productivity growth rates highlighted in Figure 1 is mostly explained by differences in GVA: average growth in ABS constant price approximate GVA over the period was -2.4 per cent but was -0.9 per cent for the National Accounts constant price estimate of GVA (Figure 2).

Figure 2: comparing manufacturing productivity components, SIC 2003

Index 1998=100

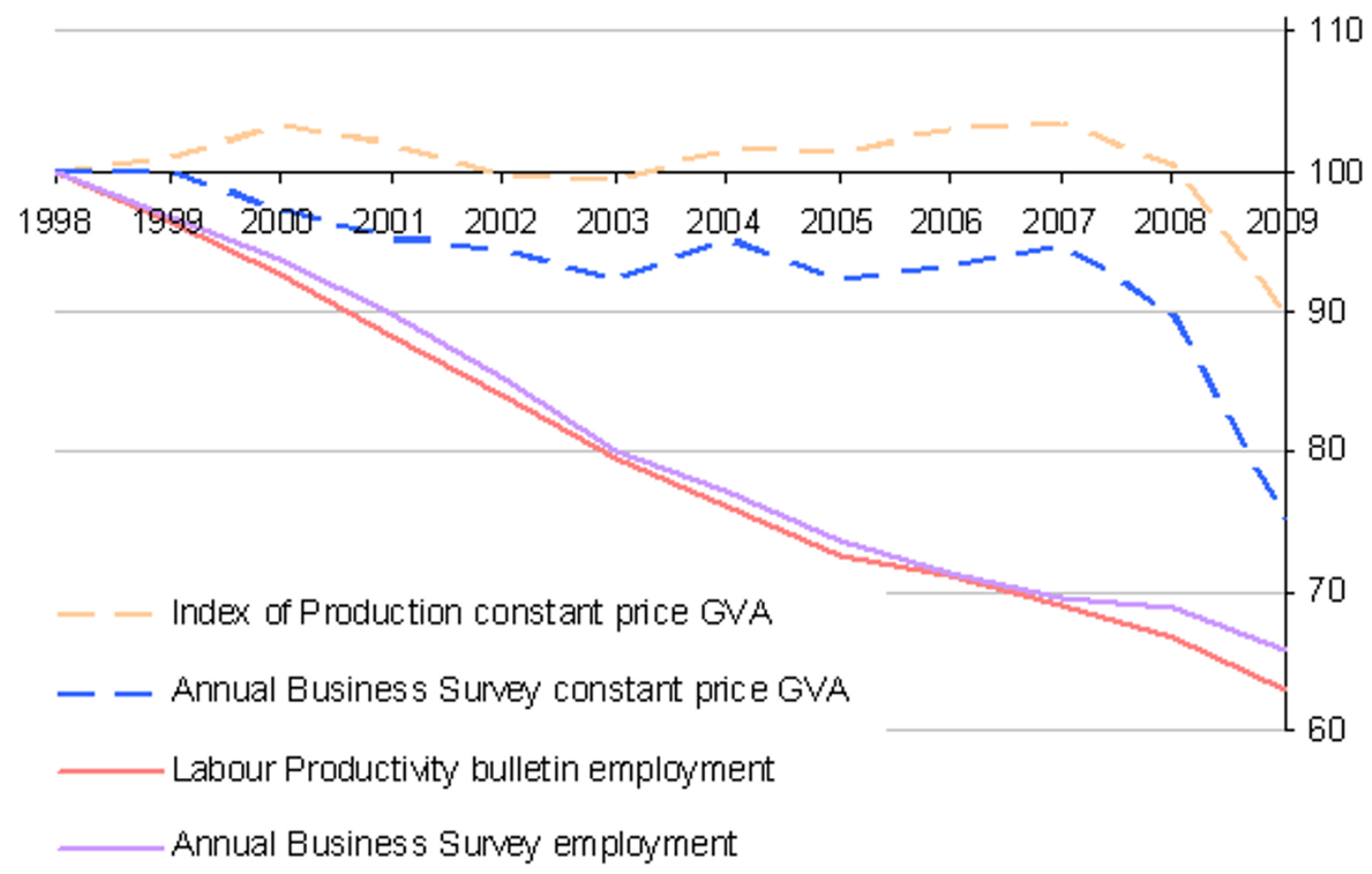

Source: Annual Business Survey (ABS) - Office for National Statistics

\section{Download chart}

\section{XLS XLS format}

$(36.5 \mathrm{~Kb})$ 
One definitional difference, as mentioned previously, is that approximate GVA from the ABS omits adjustments for taxes, subsidies or payments in kind. Additionally the GVA estimates contained in the Supply-Use framework, which go on to be used in the statistical bulletin, are subject to conceptual, quality and coherence adjustments.

The deflation methodology for both estimates also differs: current price approximate GVA from the ABS was deflated by a broad manufacturing output deflator (PLLU), which is a weighted average of lower level manufacturing PPI deflators, based on prices of home sales. The Index of Production, of which manufacturing is a part, deflates at the Supply Use Table level using a deflator which combines both a home and export deflator. The home (industry) deflator is a weighted combination of PPI (product) deflators. The export deflator is taken straight from the Export Price Indices (EPIs). Therefore, the constant price series that result from deflation will not be the same in both cases, as can clearly be seen from Figure 3 which shows the index used to deflate current price ABS estimates along with the implied deflator for manufacturing in the loP.

When annual current price manufacturing output from the Index of Production is compared with the current price ABS estimate of GVA at basic prices (Figure 3), the two series are similar for most of the time period (the exception is 2008). This suggests that deflation is a key explanation for the differences in constant price GVA in Figure 2; the order of magnitude in the difference is a clear indication of how sensitive constant price analysis can be to the choice of price index used for deflation.

Figure 3: comparing current price GVA and deflators in manufacturing, SIC 2003

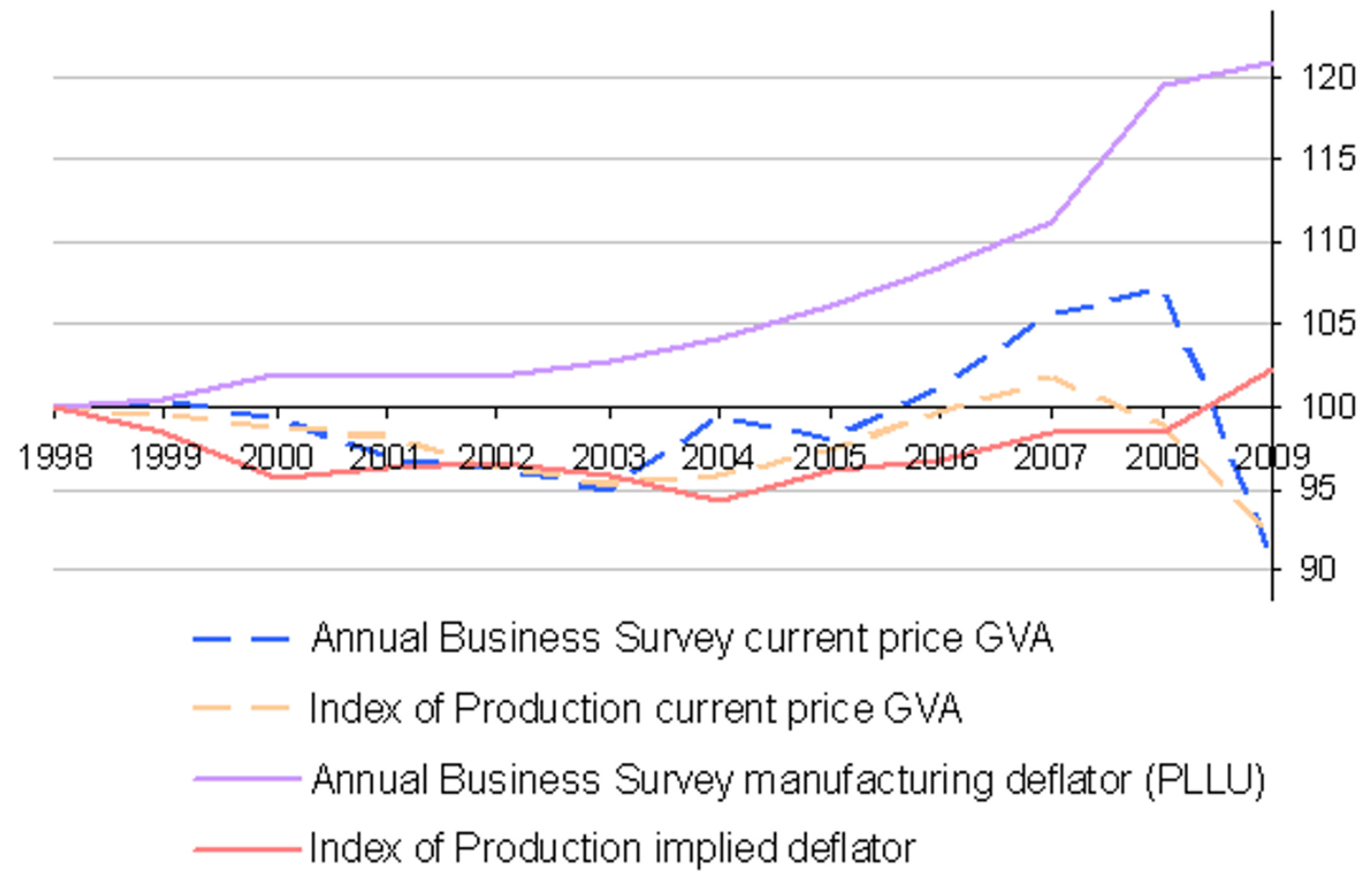


Source: Annual Business Survey (ABS) - Office for National Statistics

\section{Download chart}

XLS XLS format

$(36.5 \mathrm{~Kb})$

Figures 2 and 3 illustrate how different data sources and construction methodologies create different stories; although the broader picture remains the same here, the magnitude of change is considerably different. The differences between ABS-derived results and official published data should be borne in mind throughout the article: the two are not directly comparable.

\section{1.ii. Manufacturing in detail (Table 4)}

For 1998 to 2007, average annual productivity growth in manufacturing sub-sections in the bulletin and in the ABS is reasonably similar. However, taking the average over such a long time period will mask a certain amount of year-on-year volatility, and indeed looking at 2008 and 2009 the estimates show large differences. This is due to the methodological differences outlined above for the whole of manufacturing. In most cases where growth rates are in the same direction, the ABS estimates are of larger magnitude. In some cases the picture of the recession created using the different data is vastly different; for example, for machinery and equipment (DK), the ABS data suggest productivity growth into 2008 whereas the productivity bulletin indicates a productivity downturn started in 2008. The growth in 2008 for machinery and equipment, in ABS terms, does not appear to be driven by any one sub-industry in particular, although 29.56 (special purpose machinery not elsewhere classified) saw its (current price) productivity almost double from 2007 to 2008 (see Table A3 for detail).

Looking at the ABS results in isolation, only a handful of sub-sections in manufacturing performed better than aggregate manufacturing in both 2008 and 2009. These were Pulp, Paper and Paper Products; Publishing and Printing (DE), Rubber and Plastic Products (DH) and Electrical and Optical Equipment (DL). The only sub-section that saw positive productivity growth in 2009 was Food Products, Beverages and Tobacco (DA), although there is well-known volatility in GVA estimates for this sub-section. Strong decline over the recession for Other Non-metallic Mineral Products (DI) and Basic Metals and fabricated Metal Products (DJ) led to their productivity levels for 2009 falling below their levels in 1998; this is the only year in the series when this happens and it only occurs in these two manufacturing sub-sections. The decline in DI and DJ highlights the different productivity estimates that can result depending on the nature of manufacturing undertaken; heavy manufacturing tended to see larger drops in productivity over the downturn than more consumerfacing manufacturing.

\section{1.iii. Services in aggregate}

Although service sector productivity is not directly comparable between the official estimates and those that can be derived from the ABS due to coverage differences, roughly comparable indices show greater similarity between the two data sources for services than for manufacturing. As Figure 4 shows, employment fell by more in 2009 according to the Labour Productivity bulletin; the same is 
true of constant price GVA, although in this case the ABS also recorded a large fall. Overall, Figure 4 indicates that services productivity grew slightly faster before the recession and fell by slightly more according to the ABS estimates.

\title{
Figure 4: comparing services (part) productivity components, SIC 2003
}

\author{
Index $1998=100$
}

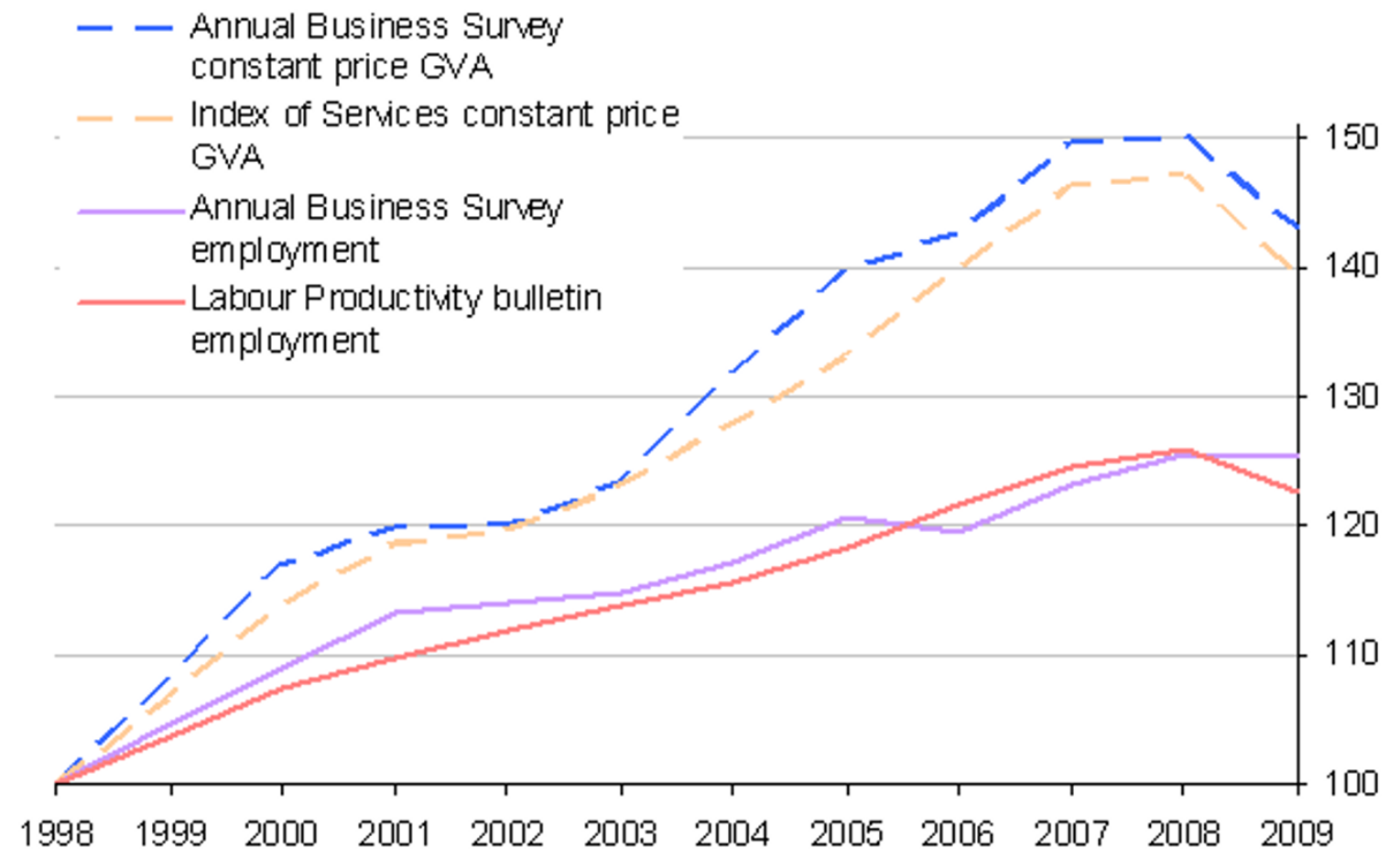

Source: Annual Business Survey (ABS) - Office for National Statistics

\section{Notes:}

1. Not all services are covered by the ABS (see Table 1 for omissions from this article due to both coverage and quality issues). In addition, the Services Producer Price Indices, which are necessary to create constant price GVA, do not cover Section $\mathrm{G}$ (wholesale and retail trade) and Division 92 (recreational, cultural and sporting activities) in enough detail, so they have been excluded from the constant price services measure for the ABS. Therefore, the part of services these ABS figures refer to - for both the constant price and current price series - is Sections $\mathrm{H}, \mathrm{I}, \mathrm{K}$ and $\mathrm{O}$ less certain divisions within these sections. (When current price results for aggregate services are published in Table A1, however, these include $G$ and 92. It is not necessary to exclude them when current price estimates are being discussed in isolation).

2. In order to make a like with like comparison with the Labour Productivity bulletin, only the divisions covered by the ABS services aggregate were used to create the current price GVA series and their GVA weights were used in the construction of a corresponding constant price GVA series. For employment, however, it was not possible to capture the ABS composition of services as the Labour Productivity bulletin does not contain enough detail on division-level employment. Labour Productivity bulletin employment, therefore, is the sum of Sections $\mathrm{H}, \mathrm{I}, \mathrm{K}$ and $\mathrm{O}$ i.e. all their divisions are included in the measure. 


\section{Download chart}

\section{XLS XLS format}

$(36.5 \mathrm{~Kb})$

Figure 5 shows that deflation of the two productivity measures is on a similar trend over the time period. It is unlikely that deflation is the key driver of differences, as is more likely to be the case with manufacturing (see Figures 2 and 3 ).

\section{Figure 5: comparing current price and deflators in services (part), SIC 2003}

Index $1998=100$

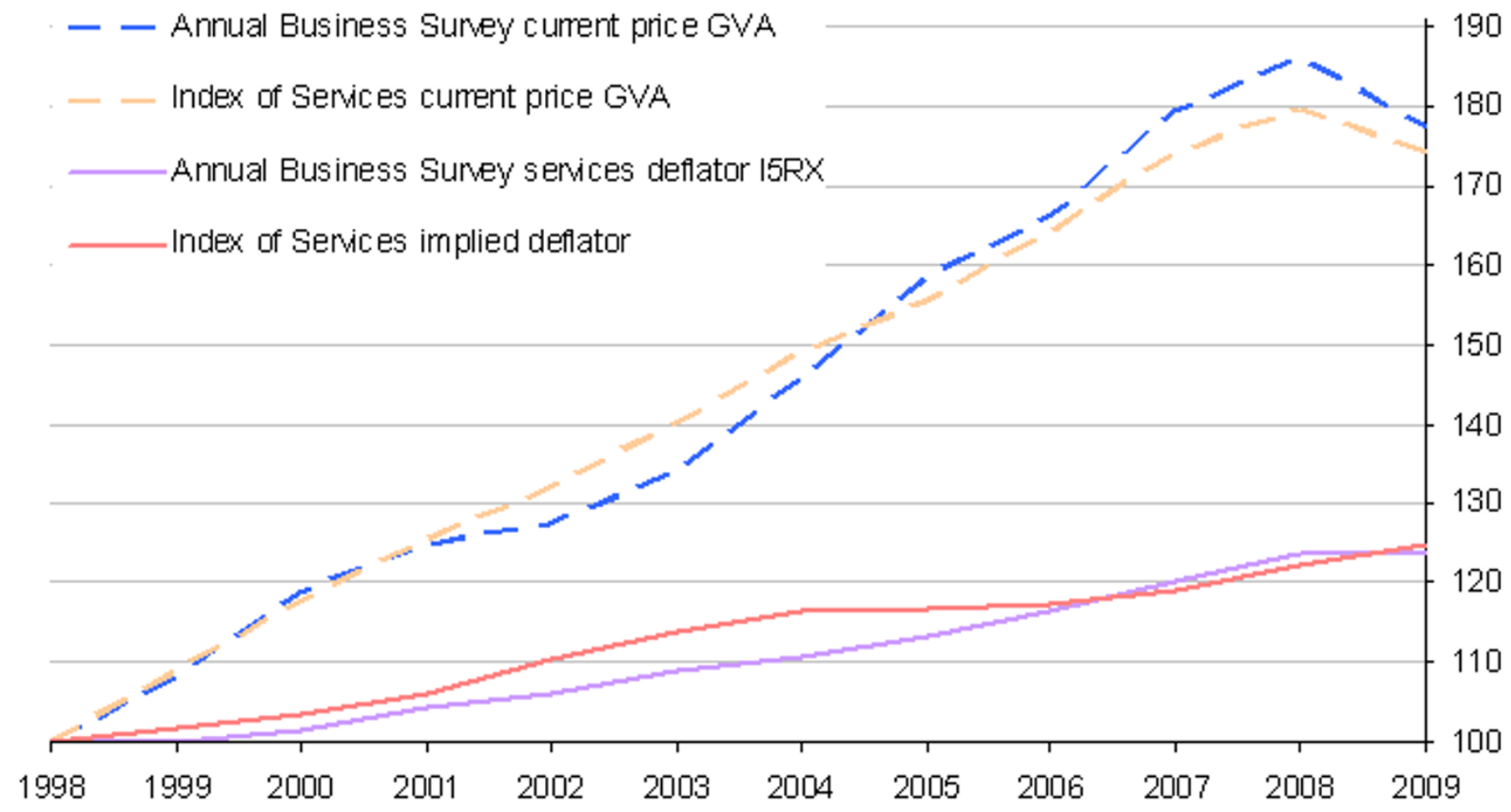

Source: Annual Business Survey (ABS) - Office for National Statistics

\section{Notes:}

1. Not all services are covered by the ABS (see Table 1 for omissions from this article due to both coverage and quality issues). In addition, the Services Producer Price Indices, which are necessary to create constant price GVA, do not cover Section G (wholesale and retail trade) and Division 92 (recreational, cultural and sporting activities) in enough detail, so they have been excluded from the constant price services measure for the ABS. Therefore, the part of services these ABS figures refer to - for both the constant price and current price series - is Sections $\mathrm{H}, \mathrm{I}, \mathrm{K}$ and $\mathrm{O}$ less certain divisions within these sections. (When current price results for aggregate services are published in Table A1, however, these include $G$ and 92 . It is not necessary to exclude them when current price estimates are being discussed in isolation). 
2. In order to make a like with like comparison with the Labour Productivity bulletin, only the divisions covered by the ABS services aggregate were used to create the current price GVA series and their GVA weights were used in the construction of a corresponding constant price GVA series. For employment, however, it was not possible to capture the ABS composition of services as the Labour Productivity bulletin does not contain enough detail on division-level employment. Labour Productivity bulletin employment, therefore, is the sum of Sections $\mathrm{H}, \mathrm{I}, \mathrm{K}$ and $\mathrm{O}$ i.e. all their divisions are included in the measure.

\section{Download chart}

\section{XLS XLS format}

$(36.5 \mathrm{~Kb})$

Overall, the differences between the two estimates of services output per job at this aggregated level can be generally explained by the definitional differences in the two measures of GVA along with the employment coverage differences, as highlighted previously in part (1.i.) of the results section.

\section{1.iv. Services in detail}

Focusing on aggregate services, as done above, hides the disparity that exists between ABS estimates and official ONS estimates of labour productivity. As can be seen in Figures 6-8, there are clear differences between the estimates at section level. That said, broadly similar trends can be inferred from the series; for example in transport, storage and communication (I) in Figure 7, both series saw accelerated growth from 2002 until 2007, but in the case of the ABS series, growth occurred at a faster pace. In the case of real estate, renting and business activities $(K)$ in Figure 8 both series experienced an upward trend in output per job over most of the period but, again, growth in the ABS series was far more pronounced.

Figure 6: constant price index of output per job in hotels and restaurants (H), SIC 2003 Index $1998=100$

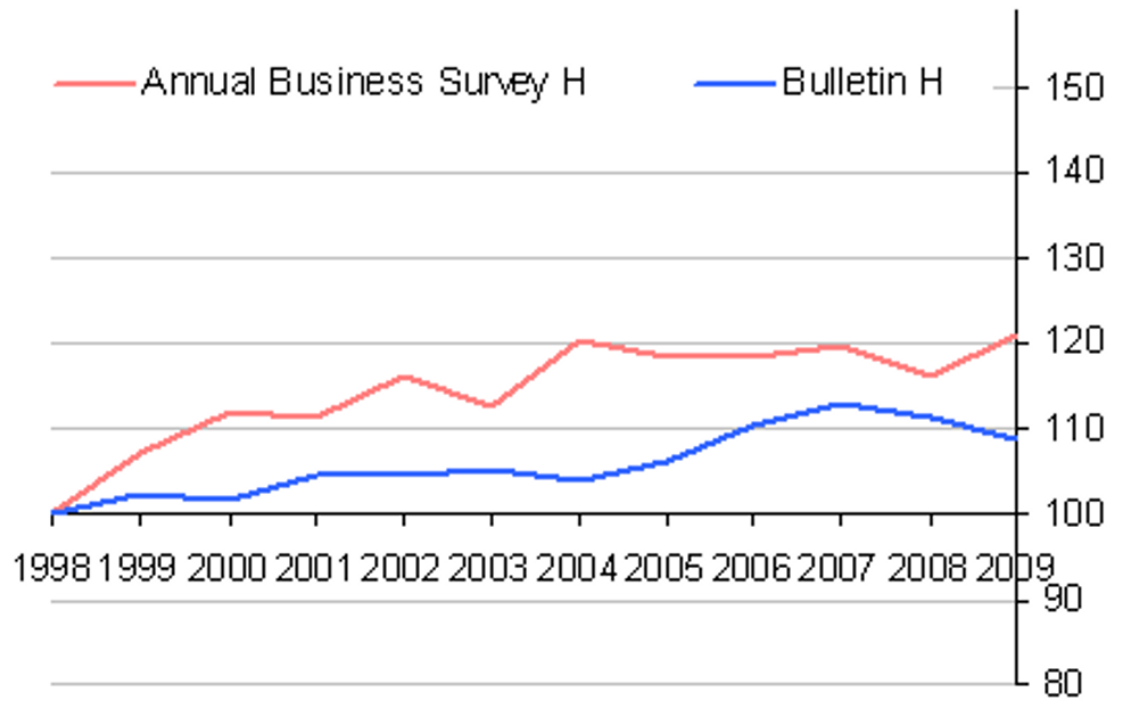


Source: Annual Business Survey (ABS) - Office for National Statistics

Notes:

1. In order to make a like with like comparison with the official estimates, only the GVA weights of the divisions covered in the ABS constant price estimates were used in the construction of a comparable constant price GVA series from the Labour Productivity bulletin. However, in the case of hotels and restaurants $(H)$, the two series exactly align (as Section $\mathrm{H}$ equals Division 55 ).

\section{Download chart}

\section{XLS XLS format}

$(36.5 \mathrm{~Kb})$

Figure 7: constant price index of output per job in transport, storage and communication (I), SIC 2003

Index $1998=100$

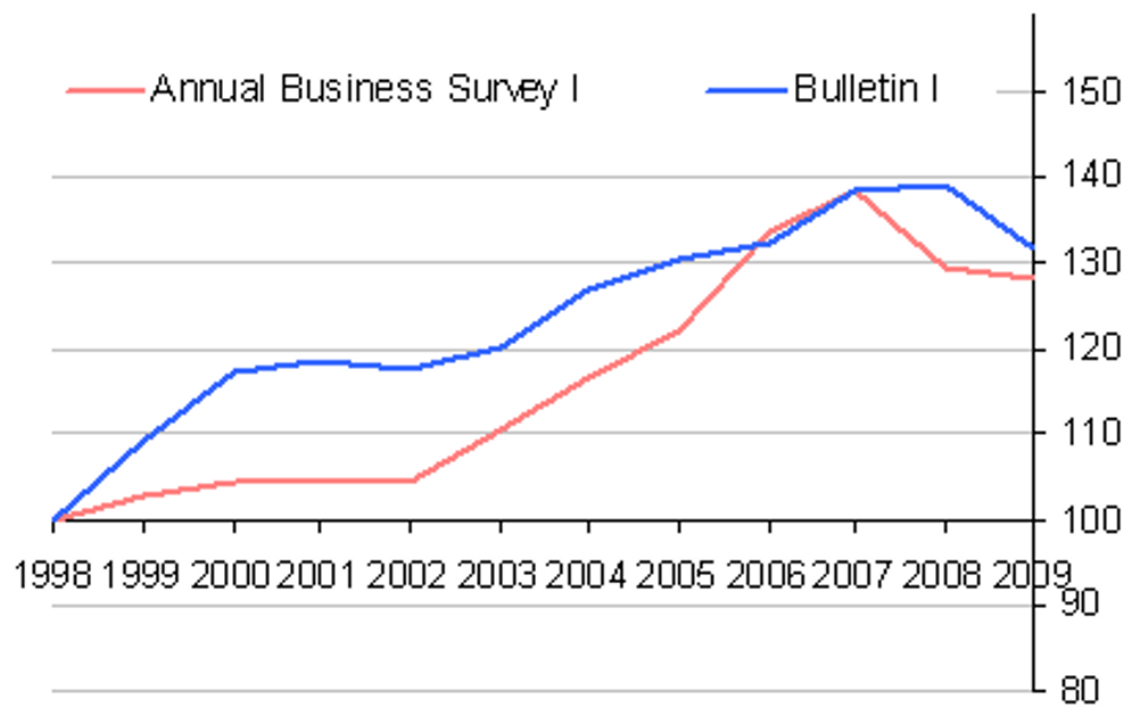

Source: Annual Business Survey (ABS) - Office for National Statistics

\section{Notes:}

1. Not all services are covered by the ABS (see Table 1 for omissions from this article due to both coverage and quality issues). Section I excludes Division 62 (Air Transport). In order to make a like with like comparison with the official estimates, only the GVA weights of the divisions covered in the ABS constant price estimates were used in the construction of a comparable constant price GVA series from the Labour Productivity bulletin. For employment, however, it was not possible to capture the ABS composition of services as the Labour Productivity bulletin does not contain enough detail on division-level employment. Therefore the bulletin estimate of employment embedded in the productivity estimate here contains Division 62.

\section{Download chart}

\section{XLS XLS format}

$(36.5 \mathrm{~Kb})$ 
Figure 8: constant price index of output per job in real estate, renting and business activities (K), SIC 2003

Index $1998=100$

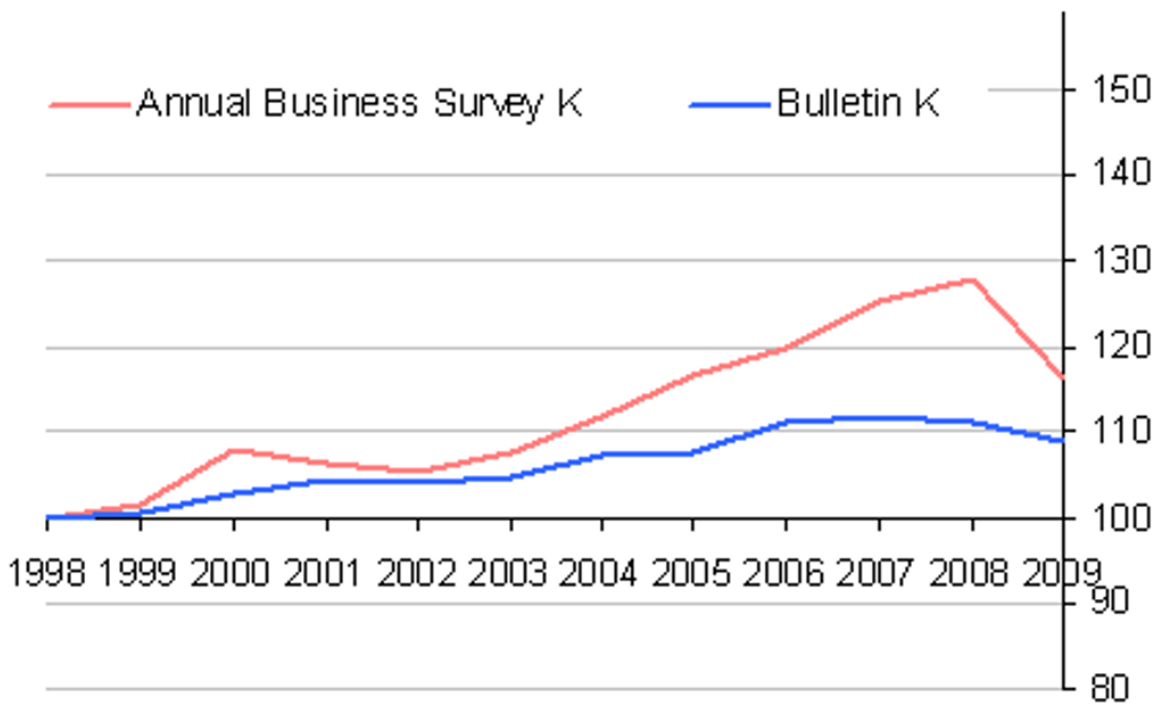

Source: Annual Business Survey (ABS) - Office for National Statistics

Notes:

1. Not all services are covered by the ABS (see Table 1 for omissions from this article due to both coverage and quality issues). Section K excludes Divisions 70 (Real Estate Activities) and 73 (Research and Development). In order to make a like with like comparison with the official estimates, only the GVA weights of the divisions covered in the ABS constant price estimates were used in the construction of a comparable constant price GVA series from the Labour Productivity bulletin. For employment, however, it was not possible to capture the ABS composition of services as the Labour Productivity bulletin does not contain enough detail on division-level employment. Therefore the bulletin estimate of employment embedded in the productivity estimate here contains Divisions 70 and 73 .

\section{Download chart}

\section{XLS XLS format}

$(36.5 \mathrm{~Kb})$

Taking the ABS results in isolation, real estate, renting and business activities $(K)$ in Figure 8 have followed a similar growth path to productivity in services in general. This is unsurprising, as it makes up over 30 per cent of services activity (using SIC 2003-based weights from 2006), the largest share of all services sections (for reference it is 23 per cent of total economic activity). Although the National Accounts estimate of $\mathrm{K}$ includes the imputed production of household services for the final consumption of owner occupiers (following international national accounts practice), the ABS-based estimate does not and could reasonably be argued to capture actual activity better (with the caveat that Division 70, real estate activities, and Division 73, research and development, are excluded due to quality issues, as mentioned previously). Productivity continued to grow in 2008, albeit at a slower rate than previously, before falling in 2009. 
Transport, storage and communication (I) had the strongest growth in labour productivity prior to the recession. This is unsurprising considering the strong growth in both capital services and capital deepening in this sector (Acheson, 2011). Productivity dropped sharply in 2008, but the pace of decline slowed considerably in 2009 , both in comparison to other parts of the services sector and to manufacturing.

Output per job in hotels and restaurants $(H)$ has been broadly flat since 2004 . This is consistent with the negative multi-factor productivity growth seen in this industry over the period (see Figure 2 in Acheson, 2011). ${ }^{1}$ Furthermore, the impact of external factors such as regulation (sanitation requirements, business hours etc.) may act as a constraint on faster productivity growth (Inklaar et al. 2008). The steep decline for other personal services (O) in 2007 is due to a large decline in output in that year (which is mainly due to a decline in sewerage and sanitary services (Division 90)). It is unlikely that this decline was cyclical (i.e. due to the economic downturn) as output rebounded somewhat in 2008 and 2009.

\section{1.v. Case-study of business activities (Figure 9, Tables 5-7)}

Business activities - here referring to divisions 71,72 and 74 - make up almost 14 per cent of all economic activity (on a SIC 2003 basis) and it is one of the few service areas covered by appropriate price deflators. Taking it as a case-study in services over 1998-2009 reveals the heterogeneity of productivity paths, even within the same industrial section (Figure 9). The impact of the recession on productivity in computer services (72) has been far less than that of other business activities (74), which include services like legal activities, accountancy and advertising. Renting services (71) is more volatile than the other two divisions and the impact of the recession is not obviously detected.

Figure 9: constant price index of output per job in business activities (K, SIC 2003) Index $1998=100$

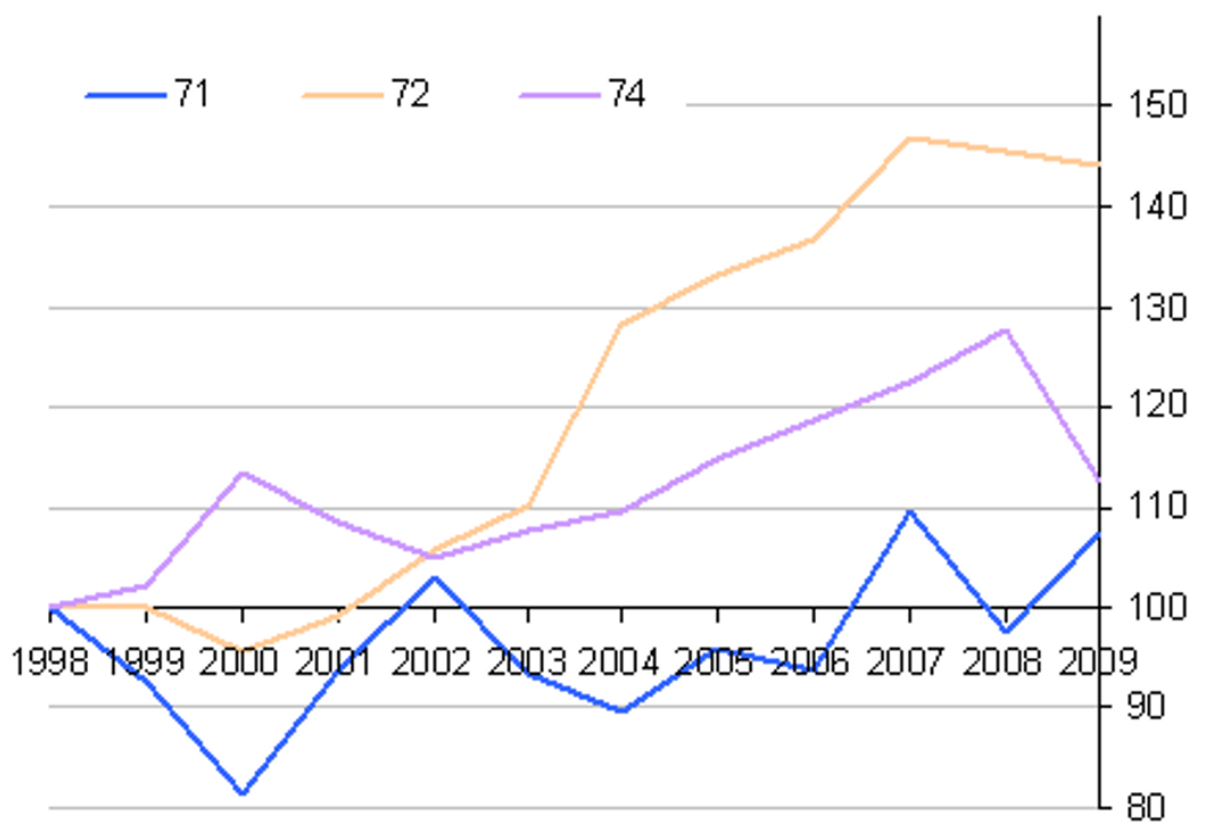


Source: Annual Business Survey (ABS) - Office for National Statistics

\section{Download chart}

XLS XLS format

$(36.5 \mathrm{~Kb})$

Detailed information on capital usage in these divisions is only available on an experimental basis (Appleton and Wallis, 2011) and is shown in Tables 5 to 7. The amount of capital available to a worker, capital deepening, is a key determinant of labour productivity. Although causation is beyond the scope of this article, capital deepening in all three divisions reflects their relative productivity growth performances quite well: for example, over 1997 to 2009 capital deepening growth in computer services was over double the growth in renting of machinery etc., and the same result holds when comparing their productivity growth in Table 5. The structural impact of capital deepening for all three industries can be roughly implied by comparing the first columns in Table 5 and Table 7.

The cyclical variation in capital deepening can most clearly be seen for computer services in both 2008 and 2009 (Table 7). This industry's ability to reallocate factor inputs quickly may be one cause of its relative resilience over the recession.

\section{1.vi. Persistence of productivity trends (Table 8)}

Table 8 presents the most variable and least variable industries in terms of constant price productivity levels from 1998 to 2009 . In the case of low variation, this serves as an indication of the persistence of productivity trends within these industries. Unsurprisingly, hotels and restaurants have shown the least variation over the time period (see also Figure 5 above). With the exception of Division 90, the most variable industries in the ABS sample have all experienced strong productivity growth over the period (see Reference Tables for further details).

\section{Analysis of nominal value added per job}

\section{2.i. Cross-sectional (Tables 9 to 12)}

Real analysis is more common than nominal analysis (as it strips out the effects of inflation). But Table 9 in nominal terms (current prices) gives an illustration of the gap between individual industries. For example, the level of productivity in manufacturing (D) lags far behind that of the other production industries $(\mathrm{C}$ and $\mathrm{E})$, reflecting the more capital intensive nature of the latter. Similarly, within services, hotels and restaurants $(H)$ consistently demonstrate low nominal value added per job - reflecting its labour intensive nature and high incidence of part-time jobs - and transport, storage and communication (I) has consistently had the highest nominal productivity. The majority of industry sections saw a fall in nominal productivity in 2009 , with the largest being in construction $(F)$.

Table 10 details the five highest and lowest performing divisions in terms of current price labour productivity levels at the two digit SIC level. Certain SIC sections at the two digit level have consistently ranked highly in terms of productivity performance. Division 11 (Oil and gas extraction) has ranked at the top for the majority of the period. Division 41 (Collection, purification and 
distribution of water) and division 23 (Manufacture of coke, refined petroleum products and nuclear fuel) have also ranked consistently highly. At the other end of the spectrum, division 55 (Hotels and restaurants) has the lowest productivity level in all years of the sample. Division 52 (Retail trade; repair of personal and household goods) also ranks consistently low in labour productivity estimates. The table brings out the clear differences between low productivity in services and high productivity in other sectors of the economy. ${ }^{2}$

The rankings in Table 10 can be expanded further by taking the average current price productivity level of each four digit industry for the entire time period and calculating the distribution of industries by decile from the resulting range of averages (Table 11). It is immediately obvious that services at the four digit level dominate the lowest decile. They are more evenly spread across the other deciles. With the exception of Divisions 11, 40 and 41 (Oil and gas extraction; electricity, gas and water supply), no divisions are represented in one decile only, which highlights the dispersion of productivity performance at a low level. Taking, for example, the manufacture of machinery and equipment (Division 29), its four digit level industries range from the third to the ninth decile i.e. average productivity levels in this industry are found in the bottom 30 per cent but also in the top 10 per cent.

Comparing Table 11 with Table 10, it is possible to see that even within poor performing divisions, such as Division 17 (manufacture of textiles) there are certain sub-industries within this that have relatively high average productivity levels, such as 17.53 (the manufacture of non-wovens) in the seventh decile. Conversely, a high productivity performance, such as that of Division 61 (Water Transport), is quite clearly driven by the sub-industry of sea and coastal water in the top decile (61.10) rather than inland water transport (61.20), which is in the fourth decile.

Other divisions are more concentrated in terms of average productivity levels, such as Division 90 (Sewage and sanitary services) in the eighth decile and above, and Division 55 (hotels and restaurants) in the lowest decile.

Looking at relative levels of productivity gives an indication of the distance of each part of the economy from the productivity frontier. Taking the highest performing sub-sector in a specific industry, for example 'sales not in store' (52.6) in retail trade, and looking at the relative performance of other sub-sectors will indicate the productivity gap for the lowest performing retail firms. This particular example is interesting as the majority of sales in 'sales not in store' are internet-based. The use of the internet is a relatively new innovation to this industry and the results in Table 12 indicate that the use of this general purpose technology in retail has strong productivity-enhancing effects. However, working patterns in this division must be borne in mind: non specialised stores (52.1) and new goods in specialised stores (52.4) are labour intensive industries compared to both sales not in store and all other sub-sections in retail trade, and this may influence the productivity results. That said, a number of other retail trade sub-sections in the table have similar or smaller employment shares to 52.6 and their distance to the productivity frontier for this industry is worth comparison.

\section{2.ii. Time series (Table 13 and Appendix Tables A1-A3)}

Although taking growth rates of current price productivity estimates does not capture the true evolution of the economy (as price changes have not been deflated out), something can still be said 
about change before and during the recession at a detailed level. Table 13 shows the industries with the greatest percentage point difference in average annual growth before and during the recession. The decline for management activities of holding companies (74.15) is notable as it is almost double that of the next worst industry. Although no greater detail is possible, its huge decline over the recession may be due to the impact of the recession on construction holding companies in particular. Only in two cases is the percentage point difference due to productivity growth increasing over the recession, renting of water transport equipment (71.22) and retail sale of tobacco products (52.26).

\section{Notes}

1. Multi-factor productivity is the efficiency with which inputs are turned into outputs; it is often described in the growth literature as 'a measure of disembodied technical change'.

2. The difficulty of measuring services output, particularly rapid quality change, may play a part in this. See (Haskel, 2007).

\section{Conclusion}

The data used in this article are more disaggregated than ONS's official productivity estimates, and there are large and significant differences in the time series properties of the two sets of data. However, the advantage of greater detail must be balanced against the weakness of timeliness (typically, disaggregated data become available much later than aggregated data) and the lack of appropriate price deflators in all instances.

That said, the ABS data that has been published to date does provide relevant and reasonable insight into the productivity performance of industries before and during the recession. The productivity decline in manufacturing is noticeable compared to services, but services have seen mixed performance at a more disaggregated level. Disparities in the level of capital deepening across industries play a part in explaining this.

Disaggregated analysis is also useful for identification of technological innovation and may therefore aid forecasts of the persistence of productivity trends. A combination of statistical investigation and case studies at the level of firms and industries can be helpful in identifying new general purpose technologies in their infancy, for example in the retail sector above.

With that point in mind, the detailed industry analysis above could usefully be extended by looking at other variables captured in the ABS, such as expenditure on software and other forms of capital. Finally, greater coverage for services price deflators, or more sophisticated deflation of the ABS data, would enhance the analysis considerably. 


\section{References}

1. Acheson, J. (2011) 'Multi-factor productivity: estimates for 1970 to 2009' Economic \& Labour Market Review, vol. 5, no.5, pp. 67-81 and at http://www.ons.gov.uk/ons/rel/icp/multi-factorproductivity--experimental-/estimates-for-1970-to-2009/mfp-latest-estimates.pdf

2. Appleton, J. and Wallis, G. (2011) 'Volume of capital services: estimates for 1950 to 2009', Economic \& Labour Market Review, vol. 5, no.5, pp. 46-66 and at

http://www.ons.gov.uk/ons/rel/icp/volume-index-of-capital-services--experimental-/1950-to-2009/ index.html

3. Baily, M.N. and Solow, R.M. (2001) 'International productivity comparisons built from the firm level', Journal of Economic Perspectives, vol. 15, no.3, pp. 151-172.

4. Haskel, J. (2007) 'Measuring innovation and productivity in a knowledge-based service economy', Economic \& Labour Market Review, vol. 1, no.7, pp. 27-31 and at www.ons.gov.uk/ rel/elmr/economic-and-labour-market-review/no--7--july-2007/measuring-innovation-andproductivity-in-a-knowledge-based-service-economy.pdf

5. Inklaar, R., Timmer, M. and van Ark, B. (2008) 'Market services productivity across Europe and the US', Economic Policy, vol. 23, pp. 141-94.

6. Long, K. (2010) 'Labour productivity measures from the ABI: 1998 to 2007', Economic \& Labour Market Review, vol. 4, no.5, pp. 30-43 and at http://www.ons.gov.uk/ons/rel/elmr/economicand-labour-market-review/no--5--may-2010/labour-productivity-measures-from-the-abi--1998to-2007.pdf 